\title{
Betulin Targets Lipin1/2-Meidated P2X7 Receptor as a Therapeutic Approach to Attenuate Lipid Accumulation and Metaflammation
}

\author{
Jia-Yi Dou, Yu-Chen Jiang, Zhong-He Hu, Kun-Chen Yao, Ming-Hui Yuan, Xiao-Xue Bao, Mei-Jie Zhou, \\ Yue Liu, Zhao-Xu Li, Li-Hua Lian, Ji-Xing Nan* and Yan-Ling Wu* \\ Key Laboratory for Traditional Chinese Korean Medicine of Jilin Province, College of Pharmacy, Yanbian University, Yanji, Jilin \\ Province 133002, China
}

\begin{abstract}
The present study focused on the potential mechanism of betulin (BT), a pentacyclic triterpenoid isolated from the bark of white birch (Betula pubescens), against chronic alcohol-induced lipid accumulation and metaflammation. AML-12 and RAW 264.7 cells were administered ethanol (EtOH), lipopolysaccharide (LPS) or BT. Male C57BL/6 mice were fed Lieber-DeCarli liquid diets containing $5 \% \mathrm{EtOH}$ for 4 weeks, followed by single $\mathrm{EtOH}$ gavage on the last day and simultaneous treatment with BT (20 or $50 \mathrm{mg} /$ $\mathrm{kg}$ ) by oral gavage once per day. In vitro, MTT showed that 0-25 mM EtOH and 0-25 $\mu \mathrm{M}$ BT had no toxic effect on AML-12 cells. BT could regulate sterolregulatory-element-binding protein 1 (SREBP1), lipin1/2, P2X7 receptor (P2X7r) and NOD-like receptor family, pyrin domains-containing protein 3 (NLRP3) expressions again EtOH-stimulation. Oil Red $\mathrm{O}$ staining also indicated that BT significantly reduced lipid accumulation in EtOH-stimulated AML-12 cells. Lipin1/2 deficiency indicated that BT might mediate lipin1/2 to regulate SREBP1 and P2X7r expression and further alleviate lipid accumulation and inflammation. In vivo, BT significantly alleviated histopathological changes, reduced serum alanine aminotransferase (ALT) and aspartate aminotransferase (AST) and triglyceride (TG) levels, and regulated lipin1/2, SREBP1, peroxisome proliferator activated receptor $\alpha / \gamma($ PPAR $\alpha / \gamma)$ and $\mathrm{PGC}-1 \alpha$ expression compared with the $\mathrm{EtOH}$ group. BT reduced the secretion of inflammatory factors and blocked the $\mathrm{P} 2 \mathrm{X} 7 \mathrm{r}-$ NLRP3 signaling pathway. Collectively, BT attenuated lipid accumulation and metaflammation by regulating the lipin1/2-mediated $\mathrm{P} 2 \mathrm{X} 7 \mathrm{r}$ signaling pathway.
\end{abstract}

Key Words: Betulin, Adipose metabolic disease, Metaflammation, Lipin1/2, P2X7r

\section{INTRODUCTION}

Lipids are fundamental structures in cells and tissues that are involved in regulating intracellular energy metabolism and immune function (Walther and Farese, 2012). However, massive lipids can induce metabolic disorders and inflammatory responses (Ertunc and Hotamisligil, 2016). Alcohol is a unique toxin that may perturb hepatic lipid metabolism, further inducing alcoholic liver disease (ALD) (You and Arteel, 2019). Alcoholic fatty liver disease (AFLD) is the earliest stage of ALD, and persistent excessive alcohol consumption could lead to the development of ALD from steatosis to alcoholic hepatitis, fibrosis and even cirrhosis (Addolorato et al., 2016). Currently, alcohol withdrawal is one of the most effective methods for the treatment of ALD, while the clinical efficacy is not ideal due to the limitation of patient compliance (Liu, 2014). Therefore, it is urgent to find safe and effective treatment strategies and candidates for AFLD.

During the development of AFLD, sterol regulatory-element-binding protein 1 (SREBP1) and peroxisome proliferator activated receptor $\alpha / \gamma($ PPAR $\alpha / \gamma)$ are important transcriptional regulatory factors that are involved in lipid production and fatty acid oxidation, respectively (Menon et al., 2001; Han et al., 2019). Our previous study indicated that alcohol could downregulate SREBP1 and PPAR $\alpha$ expression while upregulating PPAR $\gamma$ expression (Yao et al., 2017a). Moreover, lipin1 is a protein generated by the LPIN1 gene and can interact with other nuclear receptors to regulate lipid metabolism, such as SREBP1 and PPAR $\alpha / \gamma$ (Koh et al., 2008; Barroso et al., 2011; Song et al., 2018). Lipin2 also functions as a transcriptional coactivator for PPAR $\gamma$, similar to lipin1 (Donkor et al., 2009). These studies confirmed the critical role of SREBP1, PPAR $\alpha / \gamma$

\section{Open Access https://doi.org/10.4062/biomolther.2021.136}

This is an Open Access article distributed under the terms of the Creative Commons Attribution Non-Commercial License (http://creativecommons.org/licenses/by-nc/4.0/) which permits unrestricted non-commercial use, distribution, and reproduction in any medium, provided the original work is properly cited.
Received Aug 23, 2021 Revised Oct 19, 2021 Accepted Nov 1, 2021 Published Online Nov 24, 2021

\section{*Corresponding Authors}

E-mail:ylwu@ybu.edu.cn (Wu YL), jxnan@ybu.edu.cn (Nan JX) Tel: +86-433-2435072 (Wu YL), +86-433-2435061 (Nan JX) Fax: +86-433-2435072 (Wu YL), +86-433-2435072 (Nan JX) 
A

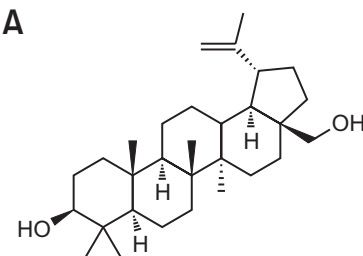

B

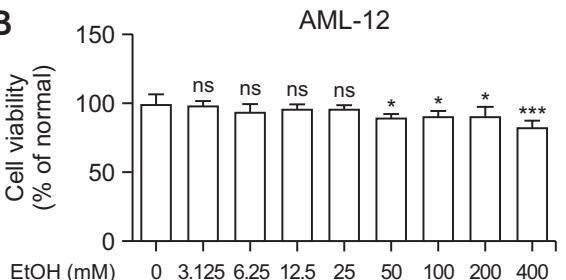

C

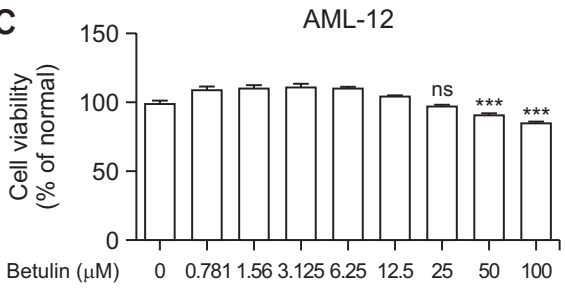

D

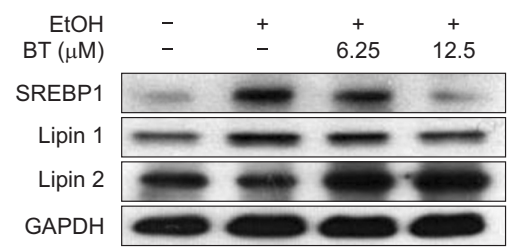

E

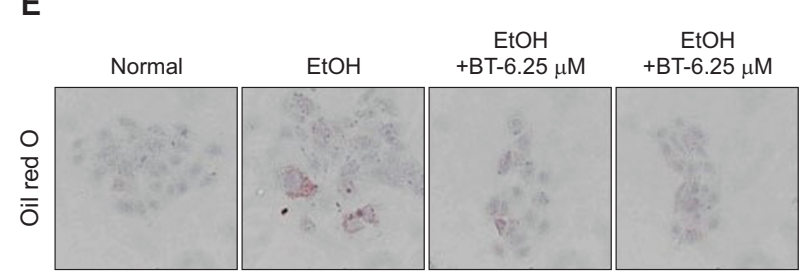

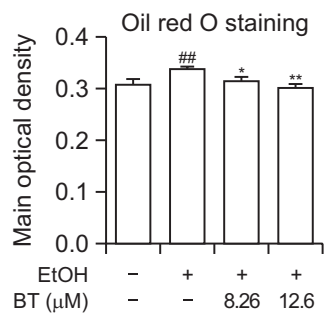

Lipin2 (IFC)
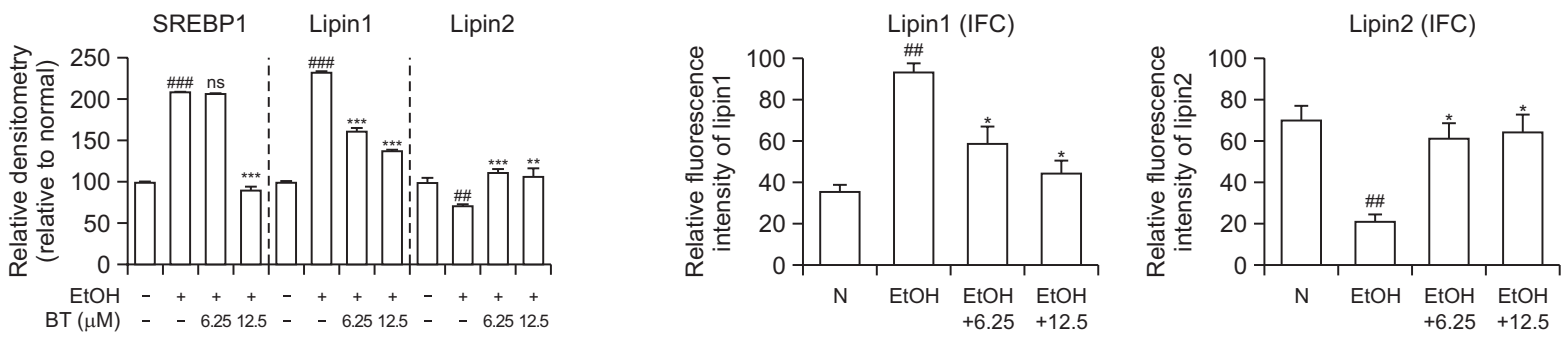

$\mathbf{F}$
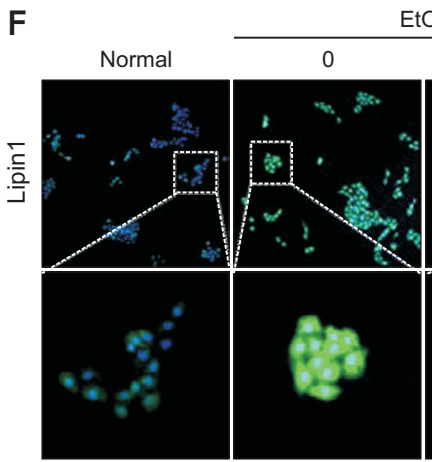

$\mathrm{EtOH}(50 \mathrm{mM})+\mathrm{BT}(\mu \mathrm{M})$

G
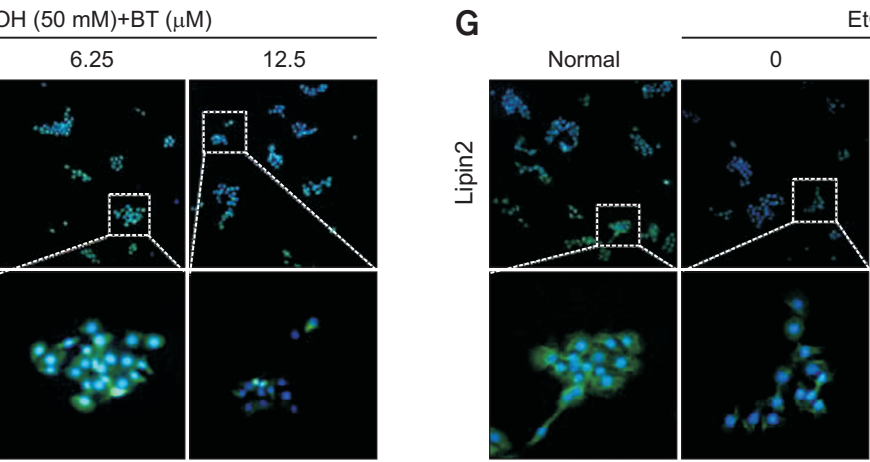

$\mathrm{EtOH}(50 \mathrm{mM})+\mathrm{BT}(\mu \mathrm{M})$

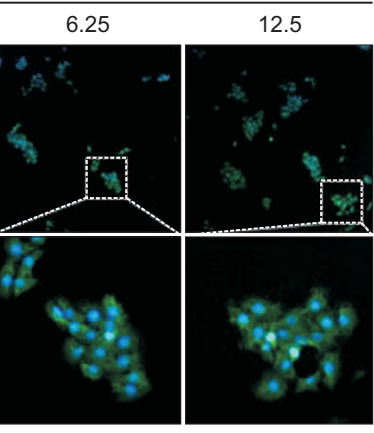

Fig. 1. $B T$ regulates lipid deposition in EtOH-stimulated AML-12 cells. (A) Chemical structure of BT. (B) Cell viability of EtOH on AML-12 cells. (C) Cell viability of BT on AML-12 cells. (D) Representative Western blotting analysis for expressions of SREBP1, lipin1 and lipin2. (E) Oil Red O staining present in 400x magnification. $(F)$ Immunofluorescence staining of lipin1 expression in AML-12 cells (100x and 600x). (G) Immunofluorescence staining of lipin2 expression in AML-12 cells (100x and 600x). The GAPDH was used as internal reference to normalize the data. ${ }^{\# \#} p<0.001,{ }^{\#} p<0.01$ vs normal group, ${ }^{*} p<0.05,{ }^{* *} p<0.01,{ }^{* * *} p<0.001$ vs EtOH group, ns, not significant. All histograms represent the mean \pm SD of at least three independent assays.

and lipin1/2 in the regulation of lipogenesis

Alcohol intake-induced excess lipid accumulation is accompanied by an inflammatory response. The $\mathrm{P} 2 \mathrm{X} 7$ receptor (P2X7r) is an ATP-gated channel and can activate the NODlike receptor family pyrin domain-containing protein 3 (NLRP3) inflammasome (Adinolfi et al., 2018). Activation of the NLRP3 inflammasome complex can induce the maturation and release of pro-IL-1 $\beta$, pro-IL-18, and pro-caspase-1, further promoting the inflammatory response (Shao et al., 2015; Del Campo et al., 2018). Previously, we reported that the inhibition of the P2X7r-NLRP3 inflammasome could ameliorate extracellular matrix (ECM) deposition and liver fibrosis (Hou et al., 2020). In addition, NLRP3 is involved in metabolic diseases, such as type 2 diabetes and obesity-induced inflammation (Haneklaus and O'Neill, 2015). Therefore, thorough inquiry into the relationship between inflammation and metabolism might be a new entry point for the treatment of metabolic diseases.

Betulin (BT, lup-20(29)-ene-3 $\beta, 28$-diol) is a naturally occurring pentacyclic triterpene and mainly isolated from the bark of white birch (Betula pubescens) (Fig. 1) (Grymel et al., 2019). Numerous studies have demonstrated that BT has various pharmacological effects, including anti-HIV, anti-malarial, anti-cancer activities (Alakurtti et al., 2006). Previously, we indicated that BT could ameliorate acute alcohol induced liver injury via activating SIRT1-AMPK signaling pathways (Bai et al., 2016; Yao et al., 2017b). Acute alcohol injury is mainly 
characterized by oxidative stress and inflammation without significant lipid accumulation. However, many alcoholic liver disease patients have a long history of chronic drinking and an addiction to alcoholism. In this study, the adopted model was highly close to the human's drinking pattern and could mimic the acute episode of alcoholic hepatitis after a single drunkenness of chronic alcohol dependent patients. Therefore, this model is beneficial for investigating the effect and potential mechanism of BT against alcohol induced lipid accumulation and metaflammation. Targeting lipin1/2-meidated P2X7r, the development of BT would provide scientific values against adipose metabolic disease and inflammation.

\section{MATERIALS AND METHODS}

\section{Chemical reagents}

Betulin (BT) (BET201102212) was purchased from Skyherb Technologies (Hangzhou, China). Primary antibodies of SREBP1 (ab3259), lipin1 (ab181389), lipin2 (ab176347), P2X7r (ab48871), NLRP3 (ab4207), FANS (ab22759), PPAR $\gamma$ (ab19481) and GAPDH (ab8245) were purchased from Abcam (Cambridge, MA, USA). Primary antibodies of PPAR $\alpha$ (sc-9000), PGC-1 $\alpha$ (sc-518025), IL-6 (sc-28343), IL-18 (sc133127), IL-1 $\alpha$ (sc-393998) and caspase-1 (sc-514) were obtained from Santa Cruz Biotechnology Inc (Santa Cruz, CA, USA). Primary antibody of IL-1 $\beta$ (AF-401-NA) was purchased from R\&D. Horseradish peroxidase (HRP)-conjugated goat anti-rabbit (ab97051) and rabbit anti-mouse (ab6728) were purchased from Abcam. Horseradish peroxidase (HRP)conjugated rabbit anti-goat (HAF017) was purchased from R\&D. The BCA Protein Assay Kit was obtained from Beyotime (Jiangsu, China). The Mouse IL-1 $\beta$ Uncoated ELISA Kit was purchased from Invitrogen (Carlsbad, CA, USA) and mouse IL-6 ELISA Kit was obtained from NeoBioscience (EMC004; Shenzhen, China). DMSO was purchased from Sigma Chemical Co (St. Louis, MO, USA). Fetal bovine serum (FBS) and Dulbecco's modified Eagle medium (DMEM) basic (1X) were purchased from Gibco (MA, USA). All other chemical reagents were analytical grade.

\section{Cell culture and treatment}

AML-12 cells and macrophage-like murine cell line Raw 264.7 were cultured in Dulbecco's Modified Eagle's Medium (DMEM), contained with $10 \%$ fetal bovine serum (FBS), 100 $\mathrm{U} / \mathrm{mL}$ penicillin and $100 \mathrm{mg} / \mathrm{mL}$ streptomycin at $37^{\circ} \mathrm{C}$ under $5 \% \mathrm{CO}_{2}$. AML-12 cells and Raw 264.7 cells were cultured in 6 -well plates at a density of $1 \times 10^{6}$ per well, and grown to full adherence for $24 \mathrm{~h}$. The cells were treated with EtOH (50 $\mathrm{mM})$, LPS $(1 \mu \mathrm{g} / \mathrm{mL})$ or different concentrations of BT for $24 \mathrm{~h}$. Then, these cells were detected by Western blot, immunofluorescence staining or cell staining experiments, etc.

\section{MTT}

AML-12 cells were cultured in 96-well plates at a density of $1 \times 10^{4}$ per well. Until fully adherent, the cells were treated with BT $(0-100 \mu \mathrm{M})$ or EtOH $(0-400 \mathrm{mM})$ for $24 \mathrm{~h}$. Subsequently, each pore was added with 3-(4, 5 dimethylthiazol-2-yl)-2,5diphenylterazoliun bromide (MTT) for $3 \mathrm{~h}$, then added DMSO to dissolve blue crystals. The absorbance was measured at $492 \mathrm{~nm}$.

\section{Oil red $O$ staining}

AML-12 cells were washed with $1 \times$ PBS, fixed with $4 \%$ paraformaldehyde solution and permeabilized with $0.1 \%$ TritonX-100 at room temperature. After immersed in 60\% isopropanol, the cells were added Oil Red O working fluid, and counterstained with hematoxylin and sealed with glycerin gelatin. All the stained cells were examined with a light microscope (Olympus, Tokyo, Japan).

\section{Cell immunofluorescence staining}

ALM-12 cells were stimulated by $\mathrm{EtOH}(50 \mathrm{mM})$ and Raw 264.7 cells were stimulated by LPS $(1 \mu \mathrm{g} / \mathrm{mL})$ or EtOH $(50$ $\mathrm{mM})$, then cultured with or without BT. The cells were washed with $1 \times$ PBS, fixed with $10 \%$ paraformaldehyde solution and permeabilized with $0.1 \%$ TritonX-100 on ice, then blocked with $5 \%$ goat serum. The cells were incubated with primary antibodies overnight at $4^{\circ} \mathrm{C}$, and incubated with corresponding secondary antibodies at room temperature. The nucleus was stained with DAPI and photographed with Olympus IX70 fluorescence microscope (Olympus).

\section{Small-interference-RNA (siRNA) transfection}

AML-12 cells were transfected with $50 \mathrm{nM}$ control siRNA, lipin1-siRNA or lipin2-siRNA (RiboBio, Guangzhou, China) using the Lipofectamine RNAiMAX reagent (Thermo Fisher Scientific Inc., Waltham, MA, USA). The cells were then harvested $48 \mathrm{~h}$ post-transfection for followed-up experiments.

\section{Animal experiments}

Male C57BL/6 mice (body weight 20-22 g) were purchased from Changchun Yisi Laboratory Animal Technology Co., Ltd (Changchun, Jilin, China). Animals were acclimatized under $20 \pm 2^{\circ} \mathrm{C}$, relative humidity of $55 \pm 5 \%$ and a $12 \mathrm{~h}$ light-dark cycle conditions, and allowed free access to standard diet and water ad libitum. The experiment procedures followed guidelines for the care and use of laboratory animals and were approved by Yanbian University (Yanji, China) (Permission number, 20171217).

Mice were randomly divided into five groups: Normal group, EtOH group, EtOH+BT-20 group, EtOH+BT-50 group and pair-fed group. Except normal and pair fed groups, the other groups were given a Lieber-DeCarli alcoholic liquid diet containing 5\% EtOH (L-D, TP4030D, Trophic Animal Feed Hightech Co., Ltd, Nantong, China). In the first week, the concentration of EtOH in L-D diet was gradually added from $1 \%$ to $5 \%$. On the last day, all mice except for normal and pair-fed groups were given a single gavage $5 \% \mathrm{EtOH}(5 \mathrm{~g} / \mathrm{kg})$. Mice in normal group were fed with normal diet, and pair-fed group were fed with L-D control diet (TP4030C). BT groups were daily gavaged with BT ( 20 or $50 \mathrm{mg} / \mathrm{kg}$ ) for 4 weeks. After the last alcohol administration $9 \mathrm{~h}$, all mice were sacrificed under anesthesia. Blood samples and liver tissues were collected and stored at $-80^{\circ} \mathrm{C}$. The detailed process is described in Fig. 2.

\section{Determination of serum biochemical parameters}

Serum aspartate aminotransferase (AST), alanine aminotransferase (ALT) and triglycerides (TG) were determined according to the manufacturer's manufacturing instructions by Nanjing Jiancheng Bioengineering Institute (Nanjing, China).

Enzyme-linked immunosorbent assays for IL-1 $\beta$ and IL- 6 Mouse IL-1 $\beta$ and IL- 6 protein level was measured by Mouse 
A

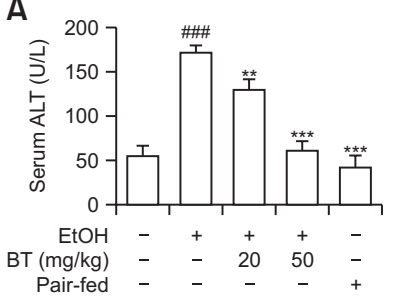

B

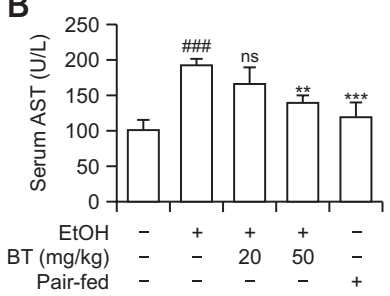

C

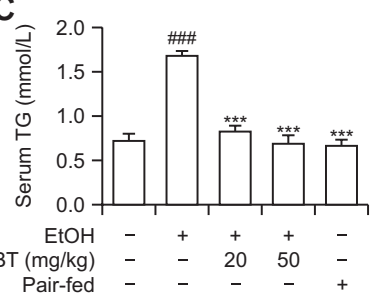

D

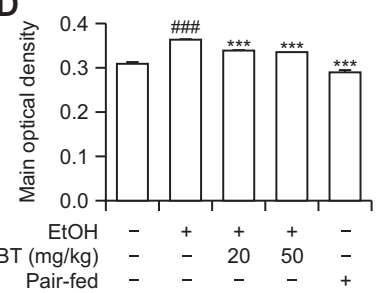

$\mathrm{E}$

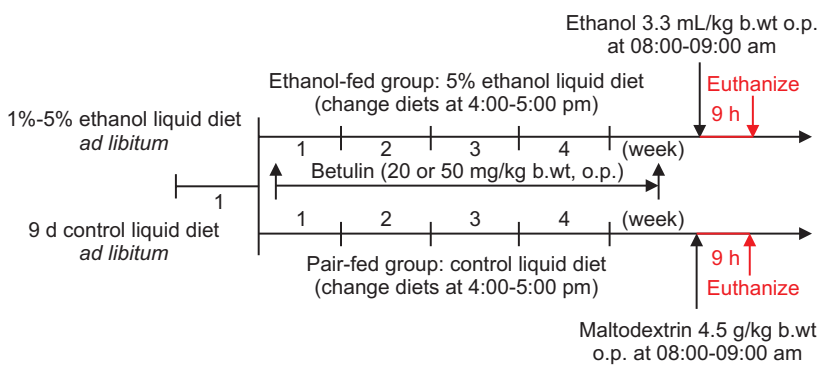

$\mathrm{F}$

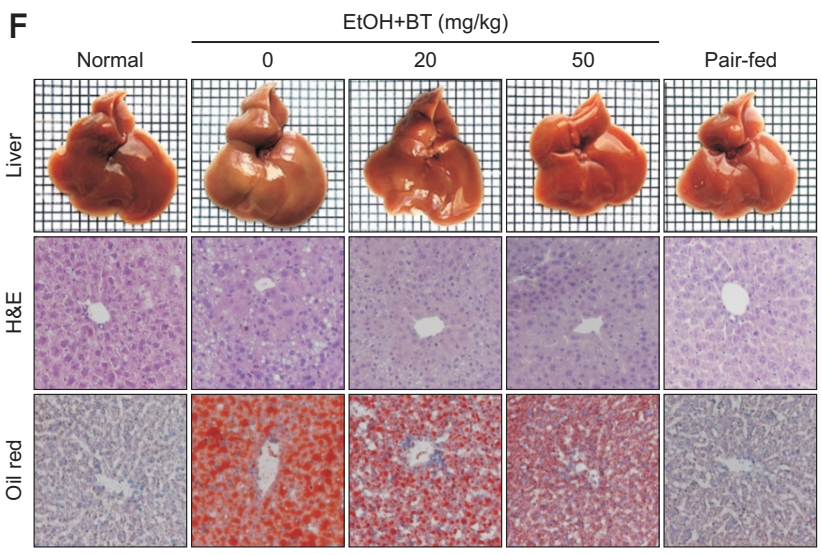

Fig. 2. BT alleviates hepatic steatosis and injury in chronic EtOH administration mice. (A) Serum ALT activities. (B) Serum AST activities. (C) Serum TG levels. (D) Positive area of Oil Red O staining was analyzed with Image Pro-Plus 6.0 (RRID:SCR_016879, Media Cybernetics, Inc., MD, USA). (E) Animal experimental design. (F) Liver appearance pictures, Hematoxylin and Eosin (H\&E) stain and Oil red O stain $(400 \times) .{ }^{\# \#} p<0.001$ vs normal group, ${ }^{* *} p<0.01$ and ${ }^{* * *} p<0.001$ vs EtOH group, ns, not significant. All histograms represent the mean \pm SD of at least three independent assays.

IL-1 $\beta$ Uncoated ELISA Kit (Invitrogen) and mouse IL-6 ELISA Kit (EMC004, NeoBioscience) according to the manufacturers' instructions.

\section{Histopathological examination}

Liver tissues were fixed with $10 \%$ formalin solution, dehydrated with $\mathrm{EtOH}$ and embedded in paraffin, then cut into 5 $\mu \mathrm{m}$ sections. For haematoxylin and eosin (H\&E) staining, liver sections dewaxing hydration, and then stained with haematoxylin and eosin. For Oil Red O staining, liver cryosections were stained with Oil Red $\mathrm{O}$ working fluid and haematoxylin. For immunohistochemistry staining, liver tissue sections antigen restoration, treated with $10 \% \mathrm{H}_{2} \mathrm{O}_{2}$ and blocking with $5 \%$ goat serum. The sections were incubated with primary and secondary antibodies, and then visualized with DAB (Maixin Biol, Fu Zhou, China). Finally, the cell nucleus was stained with hematoxylin and sealed with neutral gum. For immunofluorescence staining, liver cryosections were fixed with methanol and acetone, blocked with $5 \%$ goat serum, followed with primary antibodies, specific fluorescent antibody and DAPI. All the liver sections were performed by microscopy (TI-E, Nikon, Tokyo, Japan).

\section{Western blotting}

Protein samples were lysed by RIPA buffer. Equal quantities of protein samples were separated by sodium dodecyl sulfate-polyacrylamide gel electrophoresis (SDS-PAGE) and then transferred to polyvinylidene fluoride (PVDF) membranes (GE healthcare, Freibury, Germany). The membranes were blocked with $5 \%$ skim milk, incubated with the primary anti- bodies at $4^{\circ} \mathrm{C}$ overnight, followed with appropriate HRP-conjugated secondary antibodies, and visualized with ECL Detection Reagent (Bio-Rad, Hercules, CA, USA). The intensities of bands were quantified by Quantity One (Bio-Rad).

\section{RT-PCR}

Total RNA was extracted from liver tissue using RNA Extraction Kit according to manufacturer's protocols and its concentrations were measured by Nanodrop ND-1000 (Thermo Fisher Scientific, Wilmington, DE, USA). Samples of RNA were reverse-transcribed into cDNA. RT-PCR was performed using pre-set appropriate primers for the gen as described in Table 1. The PCR products were run on $2 \%$ agarose gel and stained with ethyl bromide. GAPDH was used as the internal to normalize transcript level of special genes.

\section{Statistical analyses}

All the data were expressed as mean \pm SD and calculated via one-way analysis of variance and Tukey's multiple comparison tests. Calculations were performed using GraphPad Prism (GraphPad Software, San Diego, CA, USA) and a value of $p<0.05$ was considered as statistically significant.

\section{RESULTS}

\section{BT regulates lipid deposition in EtOH-stimulated AML-12 cells}

We examined the effects of EtOH or BT on the viability of AML- 12 cells by MTT. AML-12 cells were treated with EtOH (0- 
Table 1. The primer sequences for RT-PCR

\begin{tabular}{|c|c|c|}
\hline Gene & Primer sequence & Product size \\
\hline \multirow[t]{2}{*}{ IL-18 } & 5'-GATCAAAGTGCCAGTGAACC-3' & 866 \\
\hline & 5'-AАCTCCATCTTGTTGTGTCC-3' & \\
\hline \multirow[t]{2}{*}{ GAPDH } & 5'-CTTGTGCAGTGCCAGCC-3' & 1254 \\
\hline & 5'-GCCCAATACGGCCAAATCC-3' & \\
\hline \multirow[t]{2}{*}{ SREBP1 } & 5'-СTTAGCСТCTACACCAACTG-3' & 4299 \\
\hline & 5'-AGGAATACCCTCCTCATAGC-3' & \\
\hline \multirow[t]{2}{*}{ IL-1 $\beta$} & 5'-GTACATCAGCACCTCACAAG-3' & 1328 \\
\hline & 5'-CACAGGCTCTCTTTGAACAG-3' & \\
\hline \multirow[t]{2}{*}{ IL-1a } & 5'-CTTGAGTCGGCAAAGAAATC-3' & 1974 \\
\hline & 5'-GAGATGGTCAATGGCAGAAC-3' & \\
\hline \multirow[t]{2}{*}{$\mathrm{P} 2 \times 7 \mathrm{r}$} & 5'-AGCGGAAAGAGCCTGTCATC-3' & 3680 \\
\hline & 5'-GCAGGATGTTTCTCGTGGTG-3' & \\
\hline \multirow[t]{2}{*}{ NLRP3 } & 5'-GGTGTTGGAATTAGACAACTGC-3' & 4470 \\
\hline & 5'-TCAAAGACGACGGTCAGCTC-3' & \\
\hline \multirow[t]{2}{*}{ Caspase1 } & 5'-АСАТССТTСАТССТСАGAAAC-3' & 1533 \\
\hline & 5'-GATAATGAGGGCAAGACGTG-3' & \\
\hline \multirow[t]{2}{*}{ TNF- $\alpha$} & 5'-TCACACTCAGATCATCTTCTC-3' & 1619 \\
\hline & 5'-AGACTCCTCCCAGGTATATG-3' & \\
\hline \multirow[t]{2}{*}{ IL-6 } & 5'-TCСТСTCTGCAAGAGACTTC-3' & 1087 \\
\hline & 5'-CCAGTTTGGTAGCATCCATC-3' & \\
\hline
\end{tabular}

$400 \mathrm{mM})$ and $\mathrm{BT}(0-100 \mu \mathrm{M})$ for $24 \mathrm{~h}$. The results showed that EtOH (0-25 mM) and BT (0-25 $\mu \mathrm{M})$ had no effect on AML-12 cell viability (Fig. 1B, 1C). Oil Red $\mathrm{O}$ staining results showed that the red-stained lipid droplets stimulated with $\mathrm{EtOH}(50$ $\mathrm{mM}$ ) were obviously alleviated by BT treatment (Fig. 1D). In EtOH-stimulated AML-12 cells, the expression of SREBP1 and lipin1 was significantly increased, and the expression of lipin2 was decreased compared with that in the normal group. BT treatment effectively downregulated the expression of SREBP1 and lipin1 and upregulated the expression of lipin2 compared with EtOH treatment (Fig. 1E). The same results were obtained by immunofluorescence (Fig. 1F, 1G). Thus, BT could ameliorate lipid accumulation by mediating SREBP1 and lipin1/2 in EtOH-stimulated AML-12 cells.

\section{BT ameliorates the inflammatory response by blocking P2X7r-NLRP3 activation in AML-12 or RAW 264.7 cells stimulated with EtOH or LPS}

In EtOH-stimulated AML-12 cells, P2X7r and NLRP3 expression was significantly increased compared with that in the normal group, while BT treatment could significantly decrease P2X7r and NLRP3 expression (Fig. 3A). Immunofluorescence staining results also confirmed the above results (Fig. 3B, $3 \mathrm{C})$. These results demonstrated that BT could block P2X7rNLRP3 activation against EtOH stimulation in AML-12 cells. Moreover, the NLRP3 inflammasome is widely expressed in macrophages exposed to inflammatory stimuli, and we used RAW 264.7 cells to explore how BT regulates P2X7r/ NLRP3 in macrophages. In LPS- or EtOH-stimulated RAW 264.7 cells, P2X7r and NLRP3 expression was significantly increased compared with that in the normal group, while BT treatment significantly decreased P2X7r and NLRP3 expression (Fig. 3D). Similarly, immunofluorescence staining also showed that BT treatment could significantly downregulate the expression of P2X7r and NLRP3 caused by LPS or EtOH (Fig. $3 \mathrm{E}, 3 \mathrm{~F})$. These results suggested that BT could improve the
EtOH-induced hepatocyte inflammatory response by inhibiting P2X7r-NLRP3 reduce the activation of P2X7r-NLRP3 in LPSor EtOH-induced macrophages.

\section{Lipin 1/2 are indispensable for BT regulating lipid accumulation and metaflammation}

To further confirm that BT alleviates lipid accumulation and metaflammation by lipin1/2-meidated P2X7r, AML-12 cells were transfected with siRNA against lipin1 or lipin2 and then treated with EtOH or BT, respectively. Expression of lipin1 or lipin2 was significantly decreased by treating with an siRNA lipin1 or siRNA lipin2. Lipin1 deficiency resulted in a downregulation on SREBP1 and $\mathrm{P} 2 \mathrm{X} 7 \mathrm{r}$ expressions, while the EtOH-stimulated up-regulation of SREBP1 and P2X7r were strengthened by lipin2 deficiency. These results illustrated that $\mathrm{EtOH}$ could regulate SREBP1 and P2X7r expressions by targeting lipin1/2. In AML-12 cells with silencing lipin1, BT significantly decreased the expressions of SREBP1 and $\mathrm{P} 2 \mathrm{X} 7 \mathrm{r}$ compared with siRNA against lipin1 and $\mathrm{EtOH}$ group; lipin1-deficience promoted the regulation of BT on SREBP1 expression (Fig. 4A). In AML-12 cells with silencing lipin2, BT significantly decreased the expressions of SREBP1 and $\mathrm{P} 2 \mathrm{X7r}$ compared with siRNA against lipin2 and $\mathrm{EtOH}$ group; lipin2-deficience blocked the regulation of BT on SREBP1 and P2X7r expressions (Fig. 4B). These results suggested that BT could target lipin $1 / 2$ to block the P2X7r-NLRP3, which might be potential therapeutic strategy for BT against lipid accumulation and metaflammation caused by $\mathrm{EtOH}$.

\section{BT alleviates hepatic steatosis and injury in chronic EtOH administration mice}

Compared with the normal and pair-fed groups, serum ALT, AST and TG levels were significantly increased in the EtOH group, indicating that chronic EtOH administration could induce liver injury and lipid accumulation. BT treatment obviously downregulated these serum parameters compared with 
A

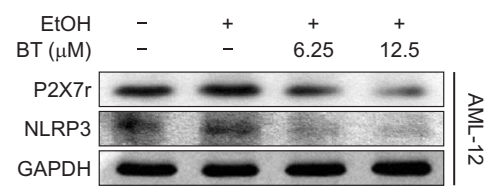

B

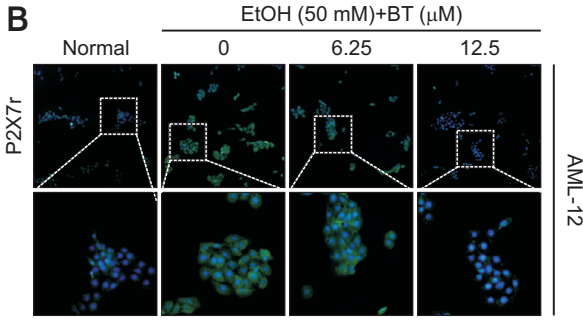

D

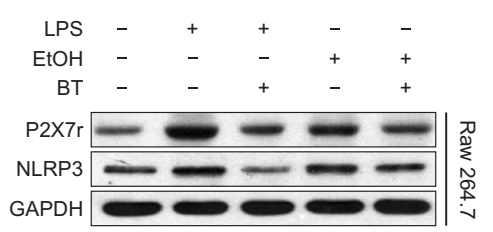

E
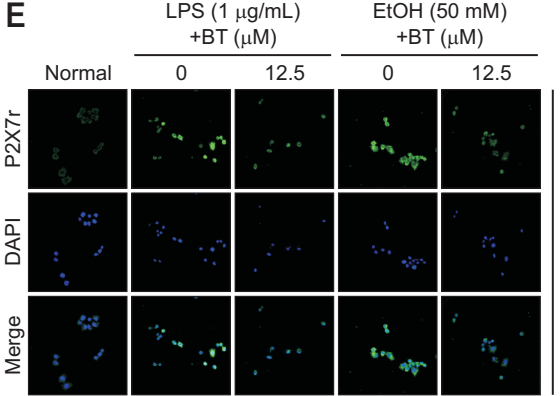
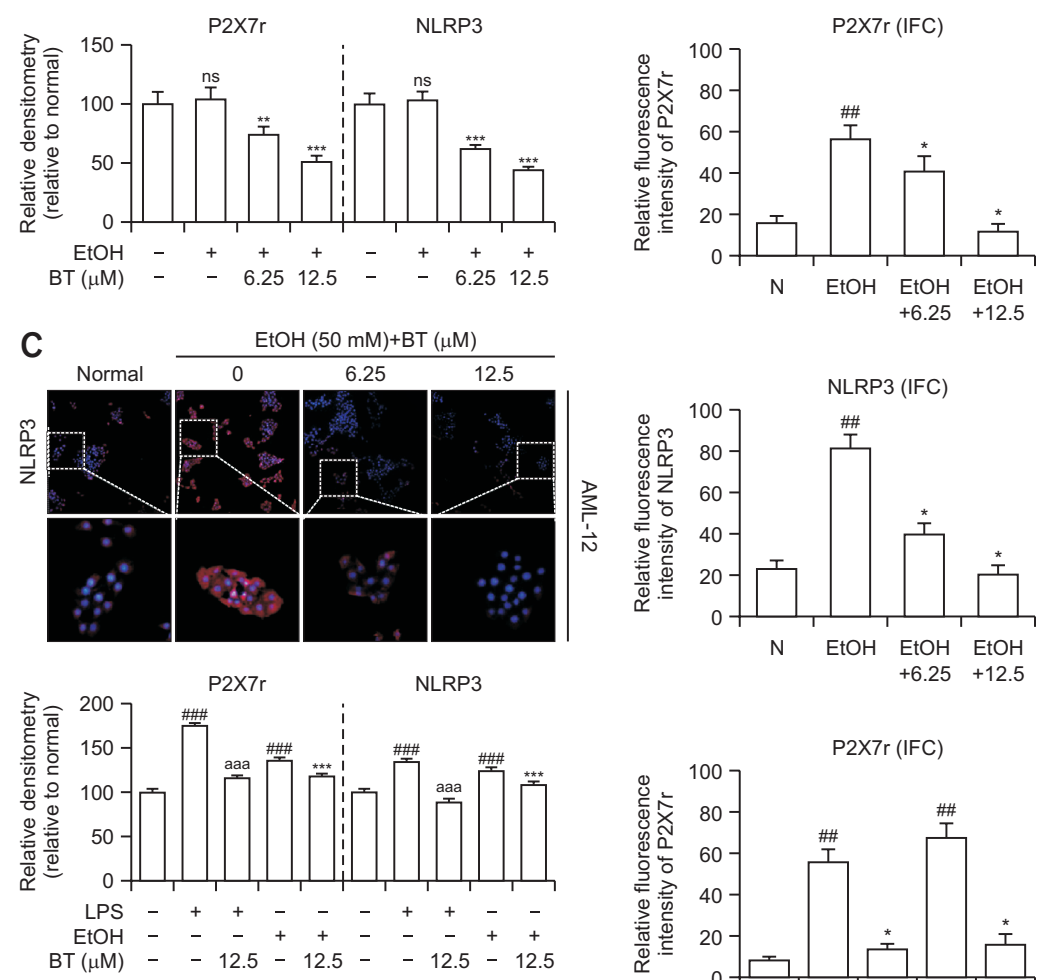

$\mathrm{F}$

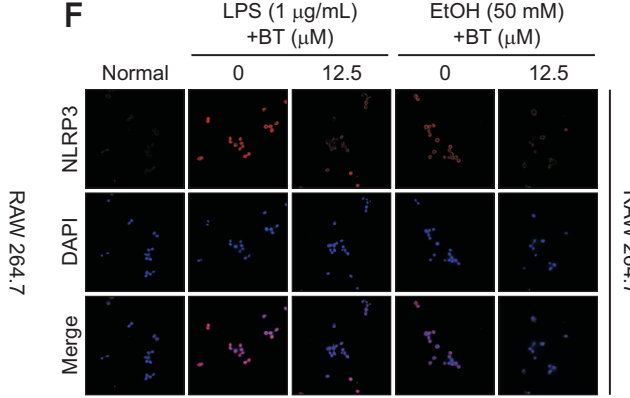

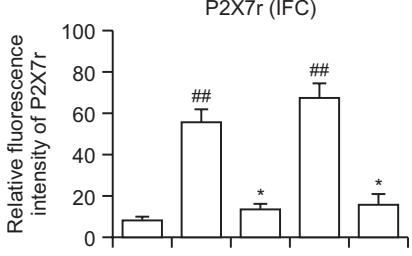

$N$ LPS LPS EtOH EtOH $+125+125$

Fig. 3. BT ameliorates the inflammatory response by blocking P2X7r-NLRP3 activation in AML-12 or RAW 264.7 cells stimulated with EtOH or LPS. (A) Representative Western blotting analysis for expressions of P2X7r and NLRP3 in AML-12 cells. (B) Immunofluorescence staining of P2X7r expression in AML-12 cells (100x or 600x). (C) Immunofluorescence staining of NLRP3 expression in AML-12 cells (100x or $600 \times$ ). (D) Representative Western blotting analysis for expressions of P2X7r and NLRP3 in RAW 264.7 cells. (E) Immunofluorescence staining of P2X7r expression in RAW 264.7 cells (600x). (F) Immunofluorescence staining of NLRP3 expression in RAW 264.7 cells (600×). The GAPDH was used as internal reference to normalize the data. For immunofluorescence staining, ${ }^{\#} p<0.01$ vs normal group; ${ }^{*} p<0.05$ vs EtOH group or LPS group. ${ }^{\# \#} p<0.001$ vs normal group, ${ }^{* *} p<0.01,{ }^{* * *} p<0.001$ vs EtOH group, ${ }^{\text {aaa }} p<0.001$ vs LPS group, ns, not significant. All histograms represent the mean $\pm \mathrm{SD}$ of at least three independent assays.

EtOH treatment (Fig. 2A-2C). Liver tissue in EtOH group appeared whitish in color and swollen compared with normal group, while these changes were reversed by BT treatment, and pair-fed group was no significant difference compared with normal group. In the EtOH group, H\&E and Oil Red O staining showed massive red-stained lipid droplets, inflammatory cell infiltration and nuclear condensation compared with the normal group, while BT treatment significantly ameliorated these histological changes (Fig. 2D, 2F). These results suggested that BT treatment could obviously relieve hepatic steatosis and injury caused by chronic $\mathrm{EtOH}$ administration.

\section{BT regulates SREBP1 and PPARa/ $/$ expression in chronic EtOH-treated mice}

SREBP1 is an important transcriptional regulator in fatty acid synthesis and results in the upregulation of triglyceride synthesis and further to fatty liver. In the EtOH group, the protein and mRNA expression levels of SREBP1 were significantly increased compared with those in the normal group and were decreased by BT treatment. In addition, chronic EtOH administration elevated the protein expression of FASN and PPAR $\gamma$ and decreased the protein expression of PPAR $\alpha$ compared with the normal group. While BT treatment significantly upregulated the expression of PPAR $\alpha$ and downregulated the expression of FASN and PPAR $\gamma$ compared with EtOH treatment (Fig. 5A). Immunohistochemical staining further 
A
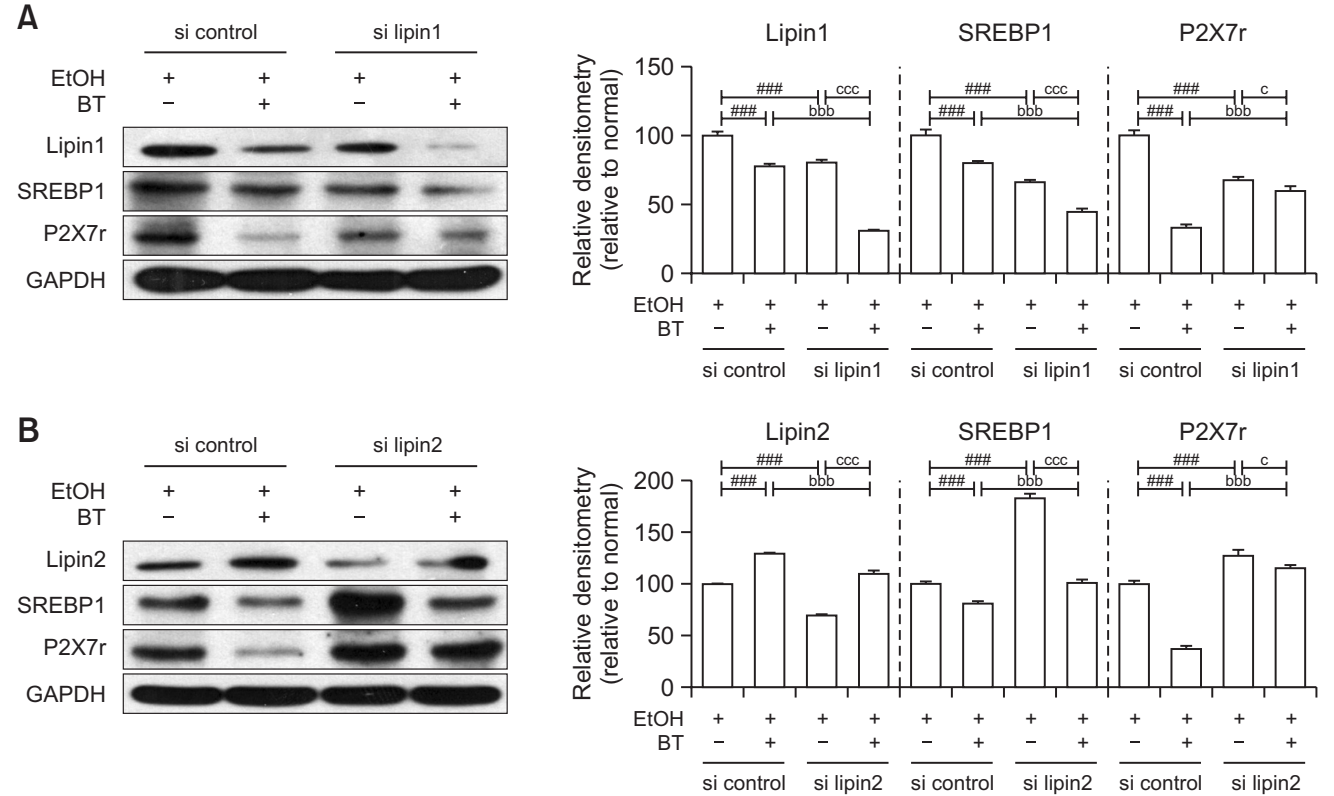

Fig. 4. BT regulates lipid accumulation and inflammatory response in AML-12 cells specifically silencing with siRNA lipin $1 / 2$. (A) Representative Western blotting analysis for expressions of lipin1, SREBP1 and P2X7r in AML-12 cells specifically silencing with siRNA lipin1. (B) Representative Western blotting analysis for expressions of lipin2, SREBP1 and P2X7r in AML-12 cells specifically silencing with siRNA lipin2. The GAPDH was used as internal reference to normalize the data. ${ }^{\prime} p<0.001$ siRNA control group vs siRNA control-BT group, ${ }^{\mathrm{bbb}} p<0.001$ siRNA control-BT group vs siRNA lipin1-BT group, ${ }^{c} p<0.05,{ }^{c c c} p<0.001$ siRNA lipin1 group vs siRNA lipin1-BT group. All histograms represent the mean \pm SD of at least three independent assays.

A

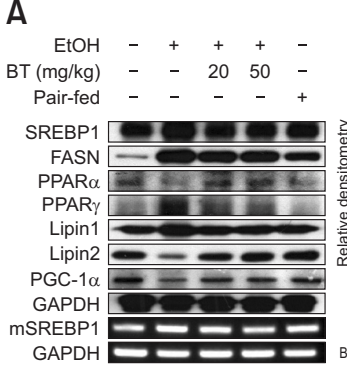

B

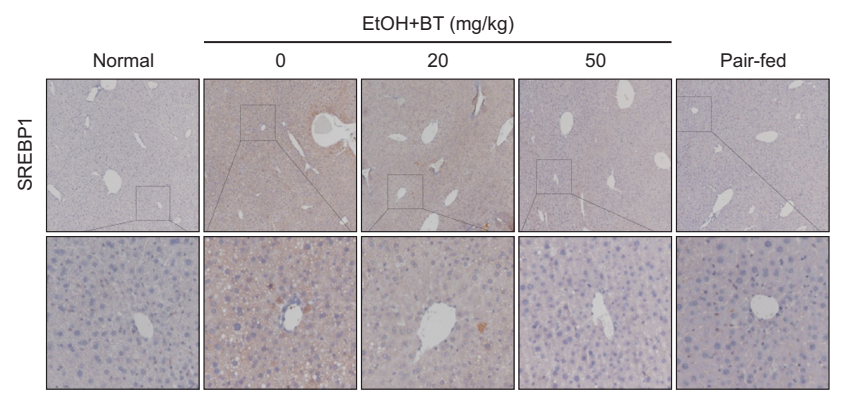

C

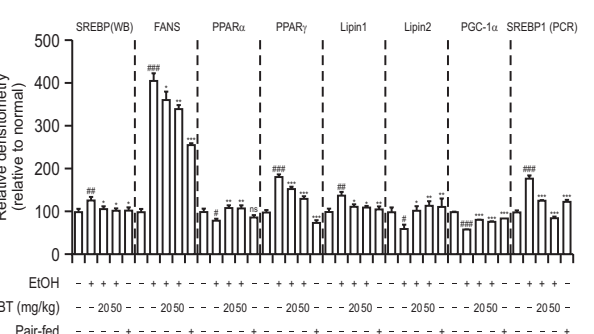

들

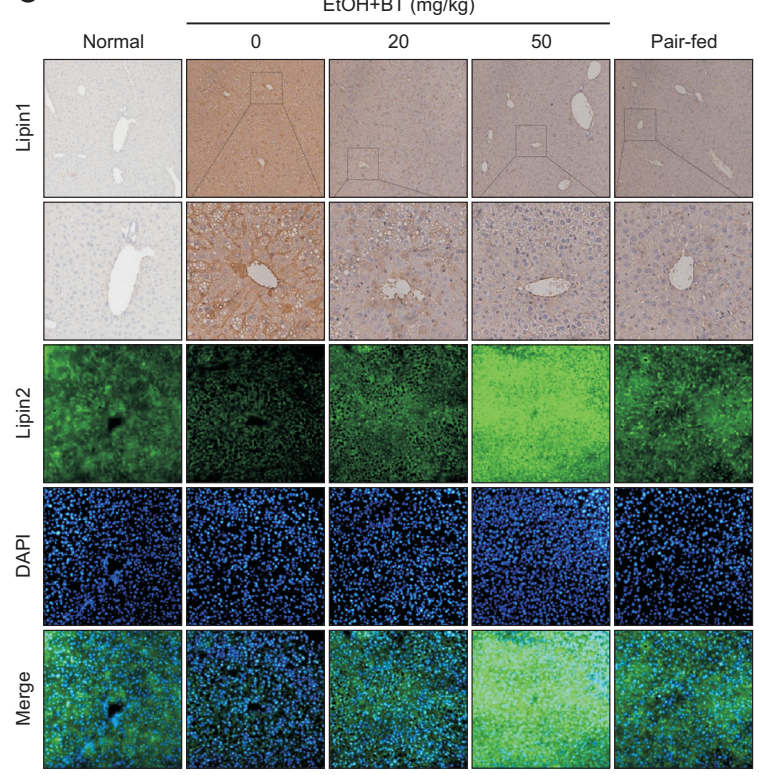

Fig. 5. BT regulates SREBP1 and PPAR $\alpha / \gamma$ expression in chronic EtOH-treated mice. (A) Representative Western blotting analysis for expressions of SREBP1, FASN, PPAR $\alpha$, PPAR $\gamma$, lipin1, lipin2 and PGC-1 $\alpha$; RT-PCR analysis for expressions of SREBP1. (B) Immunohistochemical staining of SREBP1 present in 100x and 400x magnification. (C) Immunohistochemical staining of lipin1 present in 100x and 400x magnification and immunofluorescence staining of lipin2 present in 100x magnification. Densitometric values were normalized against GAPDH. ${ }^{\# \#} p<0.001,{ }^{\# \#} p<0.01,{ }^{*} p<0.05$ vs normal group, ${ }^{*} p<0.05,{ }^{* *} p<0.01,{ }^{* * *} p<0.001$ vs EtOH group, ns, not significant. All histograms represent the mean \pm SD of at least three independent assays. 

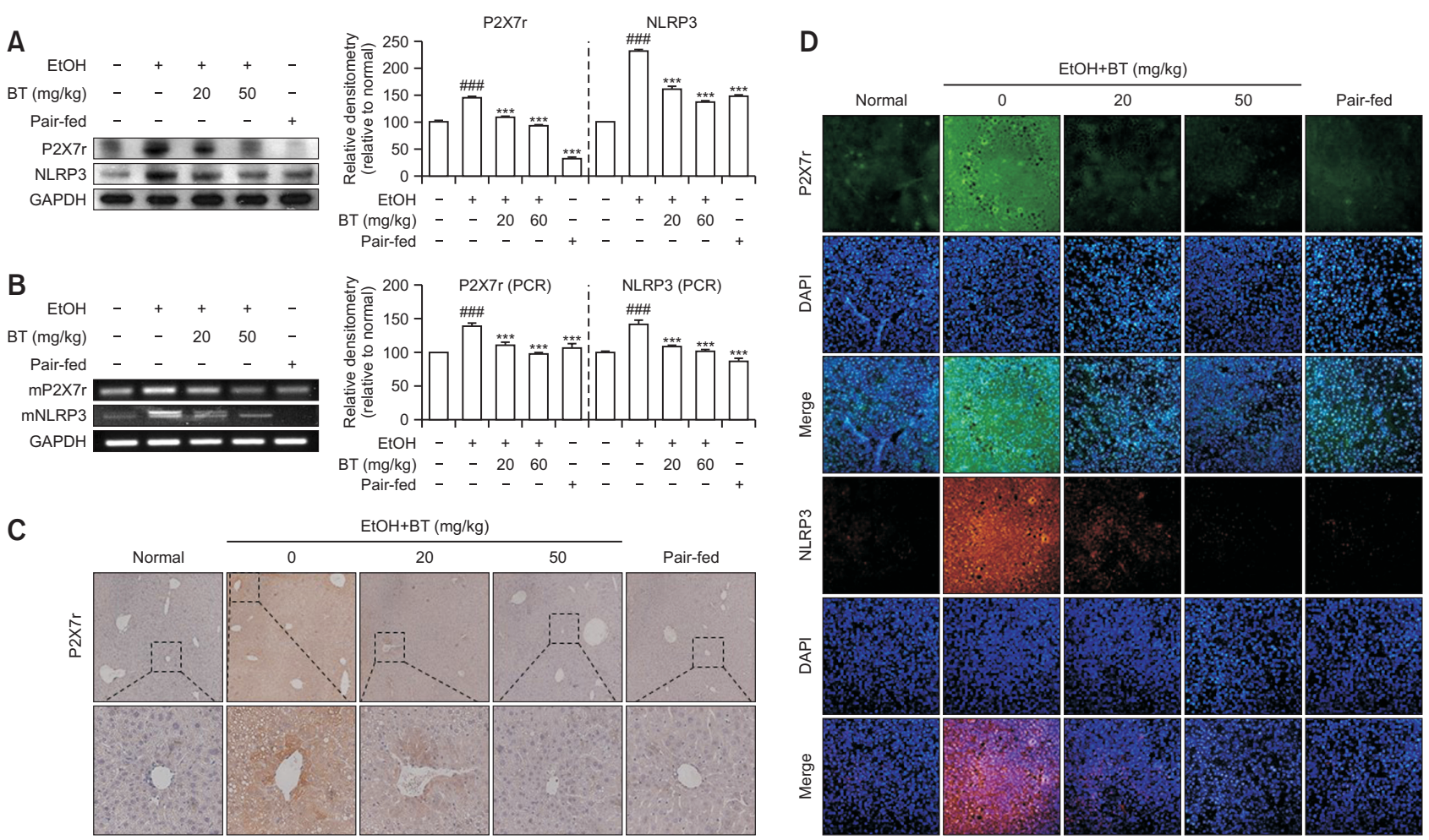

C

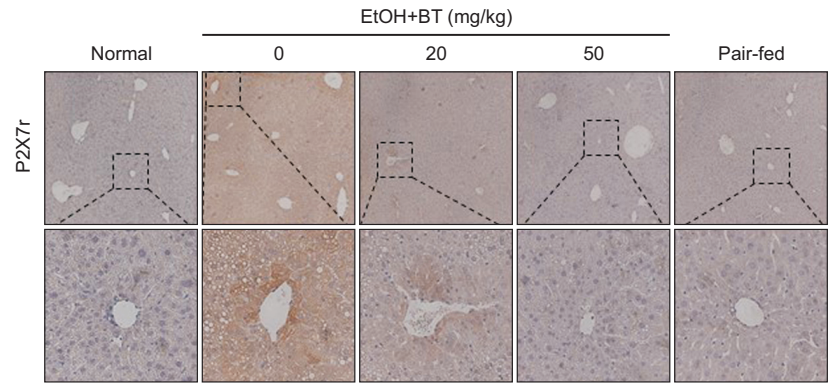
Pair-fed

Fig. 6. BT regulates $\mathrm{P} 2 \mathrm{X} 7 \mathrm{r}$ and NLRP3 expressions in chronic EtOH administration mice. (A) Representative Western blotting analysis for expressions of P2X7r and NLRP3. (B) Representative RT-PCR analysis for expressions of P2X7r and NLRP3. (C) Immunohistochemical staining of P2X7r present in 100x and 400x magnification. (D) Immunofluorescence staining of P2X7r present in 100x magnification and immunofluorescence staining of NLRP3 present in 100x magnification. Densitometric values were normalized against GAPDH. ${ }^{m} p<0.001$ vs normal group, ${ }^{* * *} p<0.001$ vs EtOH group. All histograms represent the mean $\pm \mathrm{SD}$ of at least three independent assays.

confirmed that BT could obviously decrease the positive (in brown) expression of SREBP1 caused by chronic EtOH administration (Fig. 5B). In the pair-fed group, the expression levels of SREBP1, FASN, PPAR $\alpha$ and PPAR $\gamma$ were not significantly different compared with those in the normal group (Fig. $5 \mathrm{~A})$. These results demonstrated that BT could inhibit hepatic lipogenesis in chronic EtOH-treated mice.

\section{BT regulates lipin1 and lipin2 expressions in chronic EtOH administration mice}

Chronic EtOH administration obviously increased the expression of lipin1, as well as decreased the expression of lipin2 compared with normal group. BT treatment could reverse the expressions of lipin1 and lipin2 (Fig. 5A). Immunohistochemistry and immunofluorescence staining results also confirmed that BT inhibited lipin1 expression and increased lipin2 expression caused by chronic EtOH administration (Fig. 5C). As a transcription cofactor of multiple metabolic pathways, the expression of PPAR gamma coactivator-1 $\alpha$ (PGC-1 $\alpha$ ) was decreased caused by alcohol exposure, while BT treatment increased its expression (Fig. 5A). These results showed that the regulation of lipin1/2 might be necessary for BT to alleviate lipid deposition and hepatic steatosis in chronic EtOH administration mice.

\section{BT inhibits the secretion of inflammatory cytokines by blocking P2X7r and NLRP3 expression in chronic EtOH- treated mice}

In the $\mathrm{EtOH}$ group, the protein expression levels of $\mathrm{P} 2 \mathrm{X} 7 \mathrm{r}$ and NLRP3 were significantly increased compared with those in the normal group, while BT treatment reversed the $\mathrm{P} 2 \mathrm{X} 7 \mathrm{r}$ and NLRP3 levels that were increased by EtOH challenge (Fig. 6A). RT-PCR, immunohistochemistry and immunofluorescence staining also confirmed the same results (Fig. 6B$6 D)$. To further assess the anti-inflammatory effects of BT, we used Western blot, real-time PCR and ELISA kits to examine the mRNA and protein expression levels of inflammatory cytokines, respectively. As expected, we observed high protein levels of IL-1 $\beta$ and IL- 6 in EtOH-induced mouse livers compared with normal mice, while BT treatment reduced IL-1 $\beta$ and IL-6 levels (Fig. 7A, 7B). Similarly, the protein and mRNA expression levels of IL-6, IL-18, IL-1 $\alpha$, IL-1 $\beta$, caspase- 1 and TNF- $\alpha$ were markedly increased after chronic EtOH administration and were reduced by BT treatment (Fig. 7C, 7D). These results suggested that BT could inhibit the secretion of inflammatory factors by blocking P2X7r and NLRP3, thereby alleviating the inflammatory response caused by chronic EtOH administration

\section{DISCUSSION}

The current study demonstrated that BT could obviously 
A

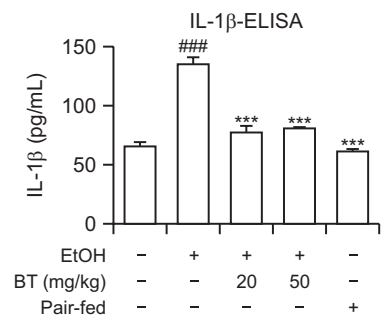

B

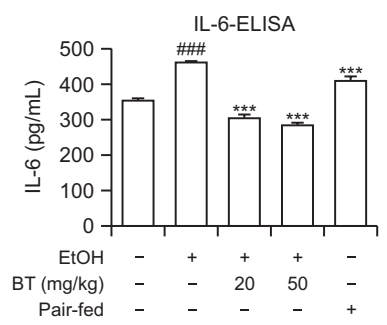

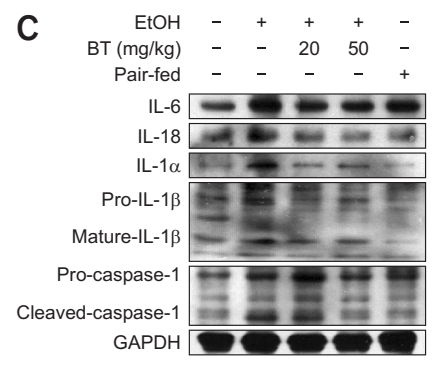

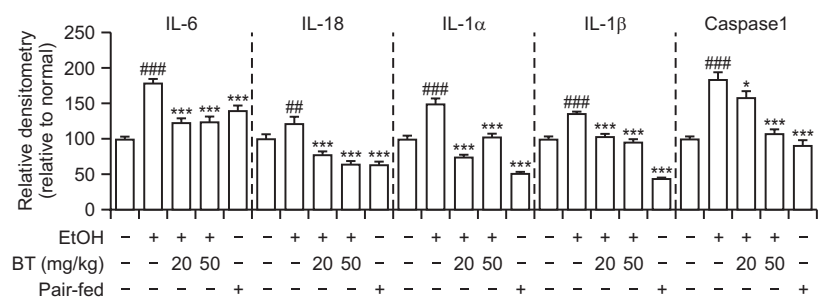

D
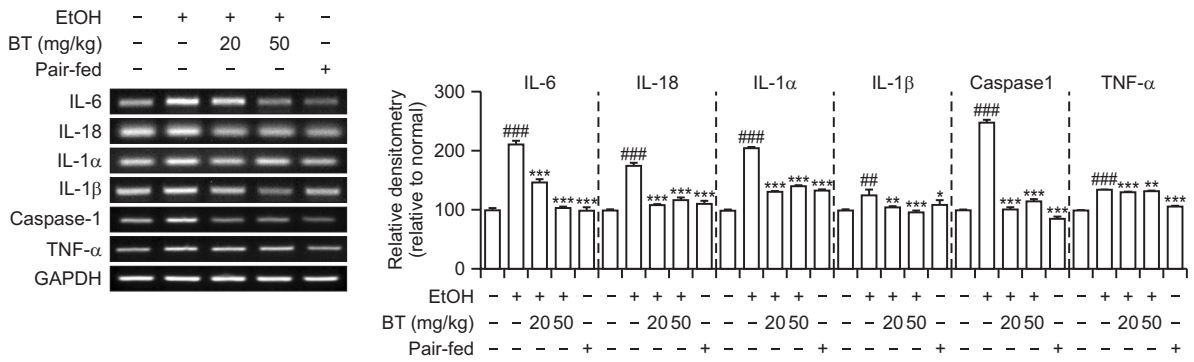

Fig. 7. $B T$ inhibits the secretion of inflammatory cytokines by blocking P2X7r and NLRP3 expression in chronic EtOH-treated mice. (A) Protein expression of IL-1 $\beta$ was determined by ELISA kit. (B) Protein expression of IL- 6 was determined by ELISA kit. (C) Representative Western blotting analysis for expressions of IL-6, IL-18, IL-1 $\alpha$, IL-1 $\beta$ and Caspase-1. (D) Representative RT-PCR analysis for expressions of IL6 , IL-18, IL-1 $\alpha$, IL-1 $\beta$, Caspase-1 and TNF- $\alpha$. Densitometric values were normalized against GAPDH. ${ }^{\# \#<0.001, ~} p<0.01$ vs normal group, ${ }^{*} p<0.05,{ }^{* *} p<0.01,{ }^{* * *} p<0.001$ vs EtOH group. All histograms represent the mean \pm SD of at least three independent assays.

ameliorate liver lipid deposition and metaflammation by reducing serum ALT, AST and TG levels, regulating SREBP1, PPAR $\alpha / \gamma$, lipin $1 / 2$ and PGC-1 $\alpha$ expressions and inhibiting inflammation factors production. Moreover, BT could inhibit P2X7r-NLRP3 signaling pathways to against lipid metaflammation, which were verified in chronic EtOH administration mice and EtOH/LPS-stimulated AML-12 cells and Raw 264.7 cells. Lipin1 deficiency suppressed SREBP1 and P2X7r expressions, while lipin2 deficiency showed the opposite results. Interestingly, the lipin1/2 deficiency significantly affected the regulation of $\mathrm{BT}$ on SREBP1 and $\mathrm{P} 2 \mathrm{X} 7 \mathrm{r}$ to further attenuate lipid accumulation and inflammation caused by $\mathrm{EtOH}$. Therefore, BT targeted lipin1/2-meidated P2X7r to ameliorate steatosis and inflammation in chronic alcoholic liver disease, which suggested that BT would be a promising therapeutic candidate for chronic alcoholic liver disease.

In previous studies, we found that BT could alleviate acute alcohol-induced liver injury (Wan et al., 2013; Bai et al., 2016). Short-term acute drinking cannot completely mimic human alcoholic liver disease, whereas long-term chronic alcohol accumulation can induce metabolic diseases, such as alcoholic fatty liver development to hepatitis, cirrhosis, and even liver cancer (Liu, 2014; Wu et al., 2016). To simulate chronic alcohol-induced lipid accumulation and metaflammation, the experimental animals were fed an L-D liquid diet containing $5 \% \mathrm{EtOH}$ for 4 weeks, and followed by a single $\mathrm{EtOH}$ gavage on the last day (Bertola et al., 2013). In vitro, AML-12 cells were directly incubated with medium containing $50 \mathrm{mM} \mathrm{EtOH}$.

Growing evidence has demonstrated that lipogenesis plays a key role in the development of alcoholic liver disease. SREBP1 is a key transcription factor controlling adipogenesis. Mature SREBP1 enters the nucleus and activates the transcription of genes involved in cholesterol and fatty acid synthesis (Shimano, 2000). Our previous study and other scholars' achievements have shown the evidence that SREBP1 is the key point for excessive lipid accumulation in the liver (Ruiz et al., 2014; Yao et al., 2017a; Song et al., 2018). Thus, the current study found that BT significantly inhibited the expression of SREBP1 to regulate lipid accumulation caused by EtOH. Lipin1 is a member of the lipin family, which can interact with the transcriptional coactivator PGC-1 $\alpha$ to increase hepatic fatty acid oxidation (Bi et al., 2015). In addition, PPAR $\alpha / \gamma$ are also involved in fatty acid metabolism and transport (Galli et al., 2001; Nanji et al., 2004; Han et al., 2021). In our previous studies, alcohol exposure upregulated SREBP1, FASN, PPAR $\gamma$ and lipin 1 expression and inhibited PPAR $\alpha$ activity, further limiting fatty acid degradation and increasing fat accumulation (Yao et al., 2017b; Zhang et al., 2020). As expected, our data showed that BT could reverse the changes in of SREBP1, FASN, PPAR $\alpha / \gamma$, lipin1/2 and PGC- $1 \alpha$ caused by chronic alcohol administration, further relieving relieve lipid deposition and the development of chronic alcoholic liver disease.

Except for lipid metabolism, the continuous inflammatory response could lead to inflammatory infiltration, hepatocyte necrosis and liver fibrosis, which cannot be reversed (Cui et al., 2021). P2X7r is an ATP-activated ionotropic purinergic receptor, whereas extracellular ATP is sensed by immune cells as a danger signal (Huang et al., 2014). P2X7r could mediate the maturation and secretion of interleukin-1 $\beta$ (IL-1 $\beta)$ and activate the NLRP3 inflammasome (Ferrari et al., 2006). Immature pro-IL-1 $\beta$ requires cleavage into mature IL-1 $\beta$ under the cleavage of caspase- 1 , and the activation of caspase- 1 depends on NLRP3 inflammasome complex formation (Ogura et al., 2006). In the current study, BT inhibited the activation of $P 2 \times 7 r$ and the NLRP3 inflammasome, further inhibiting the cleavage of caspase-1. Lacking the cleavage of caspase-1, immature pro-IL-1 $\beta$ could also not be cleaved into mature $\mathrm{IL}-1 \beta$, thereby exerting its anti-inflammatory activity. Moreover, studies have shown that lipin2 can reduce the $\mathrm{K}^{+}$efflux promoted by ATP and IL-1 $\beta$ production and regulate $\mathrm{P} 2 \mathrm{X} 7 \mathrm{r}$ 
pore formation. Furthermore, the production of IL-1 $\beta$ was significantly increased in lipin2 knockout human macrophages, while the primary BM-derived macrophages showed that IL-1 $\beta$ production was abrogated when key elements of the NLRP3 inflammasome were knocked out. These results revealed the importance of lipin2 in the regulation of $\mathrm{P} 2 \mathrm{X} 7 \mathrm{r}$ and NLRP3 inflammasome activation (Lordén et al., 2017). The current study found that lipin1 deficiency inhibited SREBP1 and $\mathrm{P} 2 \mathrm{X} 7 \mathrm{r}$ expressions, whereas lipin2 deficiency improved their expressions on the contrary. And BT treatment could further suppress the expressions of SREBP1 and P2X7r. Thus, BT may relieve the lipid accumulation and metaflammation caused by EtOH through targeting lipin $1 / 2$ to block the P2X7rNLRP3 signaling pathway.

In summary, the study revealed the hepatoprotective effect of BT against chronic alcohol-induced lipid accumulation and metaflammation through targeting lipin1/2-meidated $\mathrm{P} 2 \mathrm{X} 7 \mathrm{r}$ signaling pathway, which supplied fundamental experimental support and potential clinical value. However, it's still needed to subsequent deeper study to explore the metabolism, bioavailability and drug delivery system of BT before applications.

\section{CONFLICT OF INTEREST}

The authors declare no conflict of interest.

\section{ACKNOWLEDGMENTS}

The authors express their gratitude to the National Natural Science Foundation of China (Grant no. 81973555, and 81760668), Department of Science and Technology of Jilin Province (Grant no. 20190304084YY and YDZJ202101ZYTS106).

\section{REFERENCES}

Addolorato, G., Mirijello, A., Barrio, P. and Gual, A. (2016) Treatment of alcohol use disorders in patients with alcoholic liver disease. $J$. Hepatol. 65, 618-630.

Adinolfi, E., Giuliani, A. L., De Marchi, E., Pegoraro, A., Orioli, E. and Di Virgilio, F. (2018) The P2X7 receptor: a main player in inflammation. Biochem. Pharmacol. 151, 234-244.

Alakurtti, S., Mäkelä, T., Koskimies, S. and Yli-Kauhaluoma, J. (2006) Pharmacological properties of the ubiquitous natural product betulin. Eur. J. Pharm. Sci. 29, 1-13.

Bai, T., Yang, Y., Yao, Y. L., Sun, P., Lian, L. H., Wu, Y. L. and Nan, J. X. (2016) Betulin alleviated ethanol-induced alcoholic liver injury via SIRT1/AMPK signaling pathway. Pharmacol. Res. 105, 1-12.

Barroso, E., Rodríguez-Calvo, R., Serrano-Marco, L., Astudillo, A. M., Balsinde, J., Palomer, X. and Vázquez-Carrera, M. (2011) The PPAR $\beta / \delta$ activator GW501516 prevents the down-regulation of AMPK caused by a high-fat diet in liver and amplifies the PGC$1 \alpha$-Lipin 1-PPAR $\alpha$ pathway leading to increased fatty acid oxidation. Endocrinology 152, 1848-1859.

Bertola, A., Mathews, S., Ki, S. H., Wang, H. and Gao, B. (2013) Mouse model of chronic and binge ethanol feeding (the NIAAA model). Nat. Protoc. 3, 627-637.

Bi, L., Jiang, Z. and Zhou, J. (2015) The role of lipin-1 in the pathogenesis of alcoholic fatty liver. Alcohol Alcohol. 50, 146-151.

Cui, Z. Y., Wang, G., Zhang, J., Song, J., Jiang, Y. C., Dou, J. Y., Lian, L. H., Nan, J. X. and Wu, Y. L. (2021) Parthenolide, bioactive compound of Chrysanthemum parthenium L., ameliorates fibrogenesis and inflammation in hepatic fibrosis via regulating the crosstalk of TLR4 and STAT3 signaling pathway. Phytother. Res. 35, 56805693.

Del Campo, J. A., Gallego, P. and Grande, L. (2018) Role of inflammatory response in liver diseases: therapeutic strategies. World $\mathrm{J}$. Hepatol. 10, 1-7.

Donkor, J., Zhang, P., Wong, S., O'Loughlin, L., Dewald, J., Kok, B. P., Brindley, D. N. and Reue, K. (2009) A conserved serine residue is required for the phosphatidate phosphatase activity but not the transcriptional coactivator functions of lipin-1 and lipin-2. J. Biol. Chem. 284, 29968-29978.

Ertunc, M. E. and Hotamisligil, G. S. (2016) Lipid signaling and lipotoxicity in metaflammation: indications for metabolic disease pathogenesis and treatment. J. Lipid Res. 57, 2099-2114.

Ferrari, D., Pizzirani, C., Adinolfi, E., Lemoli, R. M., Curti, A., Idzko, M., Panther, E., and Di Virgilio, F. (2006) The P2X7 receptor: a key player in IL-1 processing and release. J. Immunol. 176, 3877-3883.

Galli, A., Pinaire, J., Fischer, M., Dorris, R. and Crabb, D. W. (2001) The transcriptional and DNA binding activity of peroxisome proliferator-activated receptor alpha is inhibited by ethanol metabolism. A novel mechanism for the development of ethanol-induced fatty liver. J. Biol. Chem. 276, 68-75.

Grymel, M., Zawojak, M. and Adamek, J. (2019) Triphenylphosphonium analogues of betulin and betulinic acid with biological activity: a comprehensive review. J. Nat. Prod. 82, 1719-1730.

Han, X., Cui, Z. Y., Song, J., Piao, H. Q., Lian, L. H., Hou, L. S., Wang, G., Zheng, S., Dong, X. X., Nan, J. X. and Wu, Y. L. (2019) Acanthoic acid modulates lipogenesis in nonalcoholic fatty liver disease via FXR/LXRs-dependent manner. Chem. Biol. Interact. 311, 108794.

Han, X., Wu, Y. L., Yang, Q. and Cao, G. (2021) Peroxisome proliferator-activated receptors in the pathogenesis and therapies of liver fibrosis. Pharmacol. Ther. 222, 107791.

Haneklaus, M. and O'Neill, L. A. (2015) NLRP3 at the interface of metabolism and inflammation. Immunol. Rev. 265, 53-62.

Hou, L. S., Cui, Z. Y., Sun, P., Piao, H. Q., Han, X., Song, J., Wang, G., Zheng, S., Dong, X. X, Gao, L., Zhu, Y., Lian, L .H., Nan, J. $X$. and Wu, Y. L. (2020) Rutin mitigates hepatic fibrogenesis and inflammation through targeting TLR4 and P2X7 receptor signaling pathway in vitro and in vivo. J. Funct. Foods 64, 103700.

Huang, C., Yu, W., Cui, H., Wang, Y., Zhang, L., Han, F. and Huang, T. (2014) P2X7 blockade attenuates mouse liver fibrosis. Mol. Med. Rep. 9, 57-62.

Koh, Y. K., Lee, M. Y., Kim, J. W., Kim, M., Moon, J. S., Lee, Y. J., Ahn, Y. H. and Kim, K. S. (2008) Lipin1 is a key factor for the maturation and maintenance of adipocytes in the regulatory network with CCAAT/enhancer-binding protein alpha and peroxisome proliferator-activated receptor gamma 2. J. Biol. Chem. 283, 34896-3906.

Liu, J. (2014) Ethanol and liver: recent insights into the mechanisms of ethanol-induced fatty liver. World J. Gastroenterol. 20, 1467214685.

Lordén, G., Sanjuán-García, I., de Pablo, N., Meana, C., AlvarezMiguel, I., Pérez-García, M. T., Pelegrín, P., Balsinde, J. and Balboa, M. A. (2017) Lipin-2 regulates NLRP3 inflammasome by affecting P2X7 receptor activation. J. Exp. Med. 214, 511-528.

Menon, K. V., Gores, G. J. and Shah, V. H. (2001) Pathogenesis, diagnosis, and treatment of alcoholic liver disease. Mayo Clin. Proc. 76, 1021-1029.

Nanji, A. A., Dannenberg, A. J., Jokelainen, K. and Bass, N. M. (2004) Alcoholic liver injury in the rat is associated with reduced expression of peroxisome proliferator-alpha (PPARalpha)-regulated genes and is ameliorated by PPARalpha activation. J. Pharmacol. Exp. Ther. 310, 417-424.

Ogura, Y., Sutterwala, F. S. and Flavell, R. A. (2006) The inflammasome: first line of the immune response to cell stress. Cell 126, 659-662.

Ruiz, R., Jideonwo, V., Ahn, M., Surendran, S., Tagliabracci, V. S., Hou, Y., Gamble, A., Kerner, J., Irimia-Dominguez, J. M., Puchowicz, M. A., DePaoli-Roach, A., Hoppel, C., Roach, P. and Morral, N. (2014) Sterol regulatory element-binding protein-1 (SREBP-1) is required to regulate glycogen synthesis and gluconeogenic gene expression in mouse liver. J. Biol. Chem. 289, 5510-5517.

Shao, B. Z., Xu, Z. Q., Han, B. Z., Su, D. F. and Liu, C. (2015) NLRP3 
inflammasome and its inhibitors: a review. Front. Pharmacol. 6 , 262.

Shimano, H. (2000) Sterol regulatory element-binding protein-1 as a dominant transcription factor for gene regulation of lipogenic enzymes in the liver. Trends Cardiovasc. Med. 10, 275-278.

Song, J., Han, X., Yao, Y. L., Li, Y. M., Zhang, J., Shao, D. Y., Hou, L. S., Fan, Y., Song, S. Z., Lian, L. H., Nan, J. X. and Wu, Y. L. (2018) Acanthoic acid suppresses lipin1/2 via TLR4 and IRAK4 signalling pathways in $\mathrm{EtOH}$ - and lipopolysaccharide-induced hepatic lipogenesis. J. Pharm. Pharmacol. 70, 393-403.

Walther, T. C. and Farese, R. V., Jr. (2012) Lipid droplets and cellular lipid metabolism. Annu. Rev. Biochem. 81, 687-714.

Wan, Y., Jiang, S., Lian, L. H., Bai, T., Cui, P. H., Sun, X. T., Jin, X. J., Wu, Y. L. and Nan, J. X. (2013) Betulinic acid and betulin ameliorate acute ethanol-induced fatty liver via TLR4 and STAT3 in vivo and in vitro. Int. Immunopharmacol. 17, 184-190.

Wu, Y. L., Zhang, Y. J., Yao, Y. L., Li, Z. M., Han, X., Lian, L. H., Zhao, Y. Q. and Nan, J. X. (2016) Cucurbitacin E ameliorates hepatic fibrosis in vivo and in vitro through activation of AMPK and blocking mTOR-dependent signaling pathway. Toxicol. Lett. 258, 147-158.

Yao, Y. L., Han, X., Li, Z. M., Lian, L. H., Nan, J. X. and Wu, Y. L. (2017a) Acanthoic acid can partially prevent alcohol exposureinduced liver lipid deposition and inflammation. Front. Pharmacol. 8, 134

Yao, Y. L., Han, X., Song, J., Zhang, J., Li, Y. M., Lian, L. H., Wu, Y. L. and Nan, J. X. (2017b) Acanthoic acid protects against ethanolinduced liver injury: possible role of AMPK activation and IRAK4 inhibition. Toxicol. Lett. 281, 127-138.

You, M. and Arteel, G. E. (2019) Effect of ethanol on lipid metabolism. J. Hepatol. 70, 237-248.

Zhang, Y., Jiang, M., Cui, B. W., Jin, C. H., Wu, Y. L., Shang. Y., Yang, H. X., Wu, M., Liu, J., Qiao, C. Y., Zhan, Z. Y., Ye, H., Zheng, G. H., Jin, Q., Lian, L. H. and Nan, J. X. (2020) P2X7 receptor-targeted regulation by tetrahydroxystilbene glucoside in alcoholic hepatosteatosis: a new strategy towards macrophage-hepatocyte crosstalk. Br. J. Pharmacol. 177, 2793-2811. 